\title{
Observation of behavior, inference of function, and the study of learning
}

\author{
WILLIAM TIMBERLAKE and FRANCISCO J. SILVA \\ Indiana University, Bloomington, Indiana
}

\begin{abstract}
Before the present century, the primary means of studying animals was observation of the form and effects of their behavior combined with presumption of their intent. In the present century, ethologists continued to emphasize observation of form and replaced presumption of intent with the study of proximate function and evolution. In contrast, most learning psychologists minimized both observation of form and presumption of intent by defining behavior in terms of simple environmental effects and establishing intent by deprivation operations. We discuss advantages of the use of observation in the study of learning, examine arguments that it is unnecessary, irrelevant, and unscientific, and consider some practical considerations in using observation. We conclude that observation of the form of behavior and concern with its ecological function should be an important part of the arsenal of techniques used to study learning.
\end{abstract}

Observation has been the dominant method of studying the behavior of animals since the beginning of recorded history (Warden, 1927). Observation provided the underpinnings of the writings of systematists such as Aristotle (384-322 B.C.) and Darwin (1859), story tellers such as Seton (1913) and Kipling (1894), collectors of anecdotes such as Pliny (A.D. 23-79), Plutarch (A.D. 46-120), and the later Romanes (1882), naturalists such as Fabre (1918), L. H. Morgan (1868), and the Peckhams (1905), protoethologists such as Craig (1918) and Heinroth (1910/1985), and experimentalists (see Lubbock, 1882; C. L. Morgan, 1900; Small, 1899; Spalding, 1872). Further, these written accounts represent only a fraction of the daily observations made by hunters, gamekeepers, animal trainers, herders, farmers, and amateur naturalists (Barber, 1980; Mountjoy, 1980).

In one sense, the historical prominence of observation is uninteresting because of a lack of alternatives. Drawings, imitations of movements and sounds, and stories of intentional actions by animals have given way only recently to the precise recording of behavior by the use of microswitches, photocells, cameras, video and audio recorders, and neurophysiological techniques. Observation, though, was considerably more than a less exact precursor to precise, automated measurement of behavior. Observers influenced the nature of their data by frequently focusing on the form of behavior and by inferring the function or intent. Many were drawn to the perceived similarities between human behavior and the behavior of nonhuman an-

Completion of this manuscript was facilitated by NIMH Grant 37892 and NSF Grant IBN 9121647. We thank Peter Balsam, Kristi Bell, Eliot Hearst, Pat Kelly, Gary Lucas, Joe Pear, Kathleen Silva, and Wesley White for comments on earlier drafts of the manuscript. Please address correspondence to W. Timberlake or F. Silva, Department of Psychology, Indiana University, Bloomington, IN 47405 (e-mail: timberla@ucs. indiana.edu, or fsilva@ucs.indiana.edu). imals (Warden, 1927), anthropomorphically viewing the latter as partially disguised people enmeshed in a web of human goals, social relations, and rules (Aesop, approximately 620 B.C.; Selous, 1908). Other observers adhered to a more animal-centered description and inference of function (Craig, 1918; Huxley, 1914).

The purpose of the present paper is to briefly review the historical and current treatment of observation as it relates to the study of learning in animals, focusing particularly on the observation of response form and the inference of function. We will consider advantages of the observation of form and inference of function and important objections and impediments to their use. Our conclusion is that observation should be encouraged in the study of learned behavior, not at the price of rejecting the rigor of traditional laboratory techniques, but for the advantages that observation of form and inference of function hold for understanding the place of learning in behavior, ecology, and evolution.

\section{OBSERVATION AND THE STUDY OF LEARNING A Brief History}

For both practical and conceptual reasons, observation has provided the initial basis for the specific study of learning in animals. At a practical level, alternative techniques were lacking. At a conceptual level, early researchers in both Britain and America were interested in the relation between learning and instinctive behavior, an interest that promoted description of response form, including stimulus orientation and inference of function (Dewsbury, 1984; Thorpe, 1979; Timberlake, 1983b). For example, Spalding (1872) used visual deprivation to study experiential factors affecting development of the following response in young chicks. C. L. Morgan (1896) investigated how chicks came to avoid bad-tasting cinnabar caterpillars in the course of learning to feed. Small (1899) studied the 
ability of rats to learn mazes that were similar to their natural burrow systems.

Agreement on the use of observation was short lived. Despite sharing a commitment to experimental analysis and a rejection of romantic and vitalistic speculations about causation, European ethologists and American learning psychologists came to treat observation quite differently. Ethologists depended heavily on observation, attending to the form and timing of simple stimulusresponse units and complex sequences of naturally occurring functional behavior. In contrast, learning psychologists came to minimize the use of observation by developing automatic recording procedures applied to simple, environmentally defined responses, such as pressing a lever or entering a goalbox. Reasons for this contrast are related to the goals of each discipline and to the intellectual and social context of their origins.

Ethological research had its roots in the naturalists' exploration of how behavior adapts animals to their environments (Tinbergen, 1951; Uexkull, 1934). Also, ethologists came from a biological tradition that emphasized evolution and the use of form to classify and relate species (Lorenz, 1950). Observation provided information concerning the form, timing, and interrelation of simple units of behavior (Hinde, 1970; Lorenz, 1937; Marler \& Hamilton, 1966).

The unique contribution of the ethologists was to combine observation and experimental manipulations to link the form of behavior with its function, distinguishing between proximate utility and evolutionary history (Dewsbury, 1992; Huntingford, 1984; Lehner, 1979; Tinbergen, 1963). For example, the form and timing of the signature bob, which male desert lizards use to warn approaching competitors and attract reproductive females, identify the species, individual, and reproductive state, within the functional context of courtship. Individual and species differences in the signature bob suggest that longterm selection pressure determined the evolution of this behavior (Hunzaker, 1962; Jenssen, 1978).

Ethologists applied the same observational experimental approach to the study of learning within functional contexts. For example, Lorenz (1937) studied imprinting, the process of identification of the parent species that occurs in many fowl, by observing the form and orientation of the following behavior of ducklings and inferring its proximate and evolutionary function. Tinbergen (1951) experimentally dissected the stimulus determinants of landmark learning in wasps, which occurred as part of provisioning their offspring in underground burrows. Hailman (1967) carefully analyzed pecking by young gulls that was directed to a spot on their parents' bills. He used a combination of manipulations and observation to show how this behavior and its determinants changed with time and experience.

In marked contrast to the ethologists' dependence on observation, psychologists, after the first world war, increasingly focused on the automatic recording of a response defined by a simple environmental effect-a methodology much like that of medical physiology and physics. Concern with the form of a response was subservient to its effect on the environment (e.g. , closure of a microswitch) and the production of orderly data. In fact, Skinner (1938) explicitly argued the irrelevance of whether a rat pressed a lever with its left forepaw, right forepaw, both forepaws, hindlegs, or snout, or simply sat on it. Concern with the function of behavior was expressed by depriving the subjects and studying how complex food-getting responses could be constructed through the response-contingent presentation of reinforcers.

Reasons for the de-emphasis of observation came partly from psychologists' commitment to achieving the status and certainty of a natural science. To reach this goal, they sought to (1) clearly separate the study of learning from concerns of philosophy, introspection, anthropomorphism, and instinct; (2) develop standardized measurements and paradigms; and (3) establish and test general laws governing learning.

The sensitivity of researchers to the hold of anthropomorphism, anecdotes, and armchair speculations on the study of learning can be seen in Thorndike's (1898) complaint:

Dogs get lost hundreds of times and no one ever notices it or sends an account of it to a scientific magazine. But let one find his way from Brooklyn to Yonkers and the fact immediately becomes a circulating anecdote. Thousands of cats on thousands of occasions sit helplessly yowling, and no one takes thought of it or writes to his friend, the professor; but let one cat claw at the knob of a door supposedly as a signal to be let out, and straightway this cat becomes the representative of the cat-mind in all the books. (p. 4)

Skinner often wrote about the predilection of humans to (mis)attribute the causes for their behavior to imaginary internal dynamic forces and states. In answering criticism that a science of behavior neglects the person or self, Skinner (1974) observed, "What it [actually] neglects is a vestige of animism, a doctrine which in its crudest form held that the body was moved by one or more indwelling spirits" (p. 167).

Instinct-based explanations of behavior were not favored, because they accorded too much credit to chance and not enough to individual effort and learning. In the following, Boring (1968) summarizes John Dewey's views of evolution:

You can be impressed by the role of nature in natural selection, by the importance of chance, by the inability of acquired characteristics to effect permanent biological progress.... Or you can see how the survival of the fittest means that use and functional practicality are basic to all progress, that struggle is fundamental in the nature of human life... and that in the end the aristocracy of chance which nature establishes can be overthrown by the effectiveness of social inheritance and social evolution. (p. 276)

Researchers such as Dunlap (1919), Holt (1931), and Kuo, (1921) in his early writings, argued that animals were born with only a set of basic reflexes plus a repertoire of "utterly random movements"' (Holt, 1931, p. 30). Complex behavior was constructed through the selection of respond- 
ing by trial and error. The power of reinforcement to structure behavior was well illustrated by training animals to engage in complex and apparently arbitrary sequences of responses leading to reward. In an early example, Skinner shaped a rat he named "Pliny" to work for, carry, and deposit a marble to receive food (see "Rat Works," 1937; see also Pierrel \& Sherman, 1963).

To isolate themselves from their anthropomorphic heritage, learning psychologists sought to emulate an idealized version of the natural sciences by emphasizing standardized environments, precisely measurable, simple responses, and a small number of experimental paradigms (Glenn, Ellis, \& Greenspoon, 1992; Iversen, 1992; Marr, 1992; McPherson, 1992). Researchers noted that the physical sciences were respected in part because they had wellmade and standardized equipment instead of a hodgepodge of puzzle boxes and mazes crudely constructed of materials ranging from chicken wire to books. According to Warner and Warden (1927),

Argument regarding the need of standardized animal apparatus would seem to be altogether unnecessary in this scientific age. It is of course the crying need of the hour. Comparative Psychology has, let us hope, reached the stage when carefully worked out methodology must replace mere dabbling, where crude experimental apparatus and techniques must either be refined to keep pace with a growing science or be cast aside entirely to make way for new methods. It is more or less a waste of time to spend laborious hours taking data on ill-devised apparatus that is neither standard nor generally used in other laboratories. (p. 5)

Measurement techniques objectified outcomes in terms of simple effects on the environment. Pavlov extended the rigorous approach of medical physiology to the study of learning by measuring the quantity of salivation elicited by a stimulus predicting food. Thorndike (1911) documented changes in the latency with which cats released a catch that opened their cage. In Skinner's laboratory, a rat closed a lever-operated switch that stepped a pen across a moving strip of paper, a technique also indebted to research in physiology. Even Tolman (1938) argued that nearly all problems of psychology could be reduced to the study of simple choice responses in a maze. To further this end, he took some pains to ensure that the measurement of maze behavior was reliable (Tolman \& Nyswander, 1927).

Emulation of the natural sciences also contributed to the establishment of a limited number of experimental paradigms. Pavlov (1927) developed his conditioning paradigm by adding a predictive stimulus to a procedure for the study of digestive reflexes. Skinner extended and codified the conditioning procedure pioneered by Thorndike, in which response-contingent reward was used to modify behavior (Hilgard \& Marquis, 1940). Despite resistance from researchers such as Tolman (1932) and Young (1938), learning was viewed in terms of the procedures of either operant or classical conditioning to such an extent that these procedures were often perceived as iso- morphic with the basic processes of learning (Gormezano \& Kehoe, 1975).

Having isolated themselves from the influence of philosophy and cultural beliefs by establishing a scientific approach to the study of learning, psychologists focused on developing and testing general laws that would hold across species and circumstances. The use of presumably arbitrary stimuli and simple, environmentally defined responses was thought to increase the generality of results by reducing interference from instinctive behavior (Johnston, 1981, 1985; Timberlake, 1983b). Any remaining species-typical qualities of learning were compensated for by modifications in procedures and the design of the apparatus (Timberlake, 1990). By these means, experimenters sought to separate the general laws of learning from the specific circumstances of training.

To further ensure a place among the natural sciences, psychologists were very careful about the definition and use of concepts (Bergmann \& Spence, 1941; MacCorquodale \& Meehl, 1954). Researchers focused on concepts close to the data, made precise distinctions among them (e.g., separating hypothetical constructs and intervening variables), and employed careful operational definitions. In the operationist's view, learning was defined in terms of both the procedures that produced it and the transducing mechanisms that measured it, without reference to its form, its proximate function, or evolution.

In sum, in the years following the first world war, psychologists and ethologists diverged markedly in their use of observation of the form of behavior and inference of its function. Both were interested in the study of learning, but ethologists used extensive observation of form in seminatural settings to help place behavior within a framework of function. As a result, the ethologists' study of learning could be embedded within larger functional episodes and cycles of behavior and tied to selection pressures and a specific evolutionary history. In contrast, learning psychologists sought to isolate the study of learning from its ecological base by the development of standard experimental paradigms in well-controlled settings with automatic recording of arbitrary, environmentally defined responses. There was little apparent concern with response form (except when it was part of a schedule requirement) or function (except as captured by a deprivation operation).

\section{ADVANTAGES OF OBSERVATION IN THE STUDY OF LEARNING}

It is not our intention to argue that psychologists should embrace observation as their only analytic technique, abandoning hard-won gains in the experimental analysis, control, and quantification of learned behavior (see also Hinde, 1970; P. Martin \& Bateson, 1993). Nor do we wish to argue that psychologists have never used systematic observation-clearly a false proposition (Bindra, 1961; Miller, 1977; Watson, 1908, 1919). What we find strik- 
ing, though, is the general failure of psychologists to take advantage of available techniques for the observation of form and assessment of function in the study of learning. The form and ecological function of behavior, not the closure of a microswitch, evolved under the pressures of natural selection. Understanding the form and function of behavior is often the most direct and efficient means of making contact with complex stimulus and response relations as well as relevant neurophysiology, ecology, and evolution.

In this section we examine three advantages of observation: increased flexibility and understanding of response measures, the contribution of response form and inference of ecological function, and the integration of ethological and psychological approaches to the study of learning.

\section{Increased Flexibility and Understanding of Response Measures}

A commonly recognized advantage of observation is that it provides a flexible alternative to automatic recording of responses, facilitating the study of a broader range of questions and behaviors. In many cases the development of the hardware that is necessary to automatically transduce behavior is expensive, difficult, time consuming, and inhibiting of research. This is especially true when dealing with a new species and relatively unconstrained behavior. For example, Bitterman and his coworkers (Bitterman \& Couvillon, 1992) have profitably studied choice behavior in free-flying bees for many years by using human observers to record choices. If they had invested most of their effort in developing and debugging automatic recording of choices rather than in performing experiments, it is likely that their research would have gotten off to a much slower start.

Convenience is also an important determinant of the use of observation in studies of familiar laboratory species. For example, defining choice in a radial-arm maze as placing all four feet in an arm is essentially no different from measuring the interruption of a photobeam placed one ratlength down the arm. Observation avoids the difficulties of mounting photocells without side panels to hold them and of programming a device to automatically record both the frequency and sequence of choices. Similarly, questions about social organization and interaction are most easily studied via observation because of the demands of automatically identifying individuals (Galef, 1990).

Observation also can supplement the results obtained by an environmentally defined response measure. For example, observation of pigeons that failed to peck keylights predicting food revealed more than one type of behavior (Eldridge \& Pear, 1987). Under some conditions, the pigeons made pecking motions at and around the keylight, but without contacting it; under other conditions, they withdrew from its immediate vicinity. Boakes (1977) struggled to measure conditioning in rats by observing how often they depressed a lighted retractable lever signaling food. Observations revealed that the rats responded to the lever by nosing it upward, failing to trip the microswitch.
Moving the light from the lever to the wall above it produced downward presses, probably by eliciting response components of rearing rather than nosing.

Other examples clarify how response form interacts with experimental circumstances to produce an effect. These cases suggest that regular observation of responding is important because it can markedly affect interpretation and conceptualization of the results. For example, Bindra's (1961) observation of the maze performance of environmentally enriched and control rats led him to argue that the superior performance of the enriched rats was due to a decrease in their locomotor exploration relative to the controls, and not necessarily to a central difference in intelligence. In a similar vein, Myers (1959) found that rats conditioned with a buzzer as a conditional stimulus (CS) learned to barpress to avoid shock more rapidly than did rats with a tone CS. Observation revealed that the rats "held" the bar between shocks, and that the buzzer, but not the tone, caused a startle response that was sufficient to operate the microswitch. Observation of conditioning trials led Holland $(1979,1980)$ to hypothesize that the initial reactions of rats to an infrequent CS predicting food resembled unconditioned orienting behaviors particular to the CS. In contrast, later responding to the CS resembled behavior to the unconditioned stimulus.

\section{Response Form and Inference of Function}

A potentially more powerful use of observation lies in the combination of response form and ecological function, in which the latter is defined as the outcome that a response and its determinants typically serve in a species (Breland \& Breland, 1966). The ecological function of a response is related, but not identical, to its survival value or adaptiveness. The adaptiveness of a response usually refers to the utility of its proximal outcome (Alcock, 1993; Hollis, 1982). The ecological function of a response refers to its survival value in the evolutionary history of the species. Thus, the ecological function of a response may or may not result in a local adaptive outcome, depending on the similarity of the current situation to the circumstances in which selection occurred.

The concept of ecological function has been realized and developed in the behavior system approach. A behavior system is an organized set of sensory perceptual mechanisms, related response components, and motivational processes that evolved because they were correlated with better service of a particular function. In combination with current stimulus conditions, a behavior system can be used to predict and account for the form of responding that emerges (Fanselow \& Lester, 1988; Timberlake, 1993b; Timberlake \& Lucas, 1989; Tinbergen, 1951). Again, note that the functioning of a behavior system may or may not be locally adaptive, depending on the fit of the system and the environment.

With regard to learning, the behavior system approach assumes that learning evolved and is expressed in the context of a functioning system, such as feeding (Timberlake \& Lucas, 1989), defense (Fanselow, 1989), or re- 
production (Domjan \& Hollis, 1988). The form of the learned response should help identify, as well as be predictable from, the organization and processes of the underlying system. Recognizing and analyzing the contribution of a behavior system to the ecological function of a response should facilitate attempts to establish the relation of learning to neurophysiological, ecological, and evolutionary determinants (Fanselow, 1991; Rozin \& Schull, 1988; Shettleworth, 1983, 1993a).

Because it seems impossible that natural selection could have produced a feeding system explicitly designed to deal with artificial environments and arbitrary stimuli and responses, it might appear that a behavior system approach would not be useful in the study of learning in the laboratory. What seems to have happened, though, is that talented researchers, using animal feedback such as response orderliness, vigor of responding, and ease of conditioning, have tuned laboratory environments to engage important aspects of the feeding system of a species. The evolved flexibility of the system does the rest. For example, the traditional operant responses used in learning, such as leverpressing and maze running in rats and keypecking in pigeons, appear to be related more to organized aspects of a functional feeding system than to arbitrarily selected movements (Timberlake, 1983b, 1990; Timberlake \& Lucas, 1989).

A careful reading of Skinner's $(1932,1938,1956)$ accounts of how he developed the response of leverpressing supports this view. Although Skinner (1956) emphasized the serendipity and laziness involved in this process, it is clear that he worked carefully to develop a reliable index of feeding that was easy to record and could be modified to produce vigorous and orderly strings of learned behavior. Skinner first tried having rats traverse a runway to obtain food, but it was not a sufficiently good index of the eating response (as might be expected, given its greater similarity to searching for food than to consumption). The manipulation response of pressing a panel to gain access to food worked as a substitute for directly measuring eating (Skinner, 1932). Then, in the form of pressing a nearby lever on an intermittent schedule, manipulation served as a reliable index of more search-like behaviors. It is important to note that in the process of refining the leverpress as a general measure of reinforced behavior, Skinner (1938) systematically tuned the apparatus by changing the location of the lever, its shape, and the surrounding stimulus environment to produce the orderly effects he desired.

Using an analytic observational approach, Stokes and Balsam (1991) provided considerable further evidence that reinforced leverpressing is not an isolated and arbitrary unit of behavior by relating its form to elements of prereinforcement response organization. Timberlake (1983a, 1990) summarized evidence that maze running is based on preorganized stimulus-response mechanisms and motivational states that are arguably related to the evolution of foraging. In a similar vein, Fanselow's (1989) work with rats' defensive behavior in the laboratory indicated that the response form was related to its ecological function of decreasing contact with a predator.

Systematic observation of form and inference of ecological function often facilitate the development of questions about animal learning that could be suitable for subsequent experimentation (Galef, 1990; Lehrman, 1971; Miller, 1977). This strategy typically involves observing a behavioral phenomenon as it occurs, with little or no intervention by the experimenter, and then bringing it under experimental control to ascertain its causal, functional, and structural aspects. For example, observation of male sticklebacks in a territorial state as they court females and chase and bite intruding males suggests potential effects for several response contingencies. Given the typical strings of appetitive behavior involving females, territorial males would be expected to learn to swim through a ring (similar to swimming through the nest) to court a female. On the basis of typical appetitive behavior involving other males, territorial males would be expected to bite an intruding rod to display to a male. The opposite combination of responses and rewards should be more difficult (Sevenster, 1973).

As a second example, one of the authors (W.T.) spent several noon hours on a park bench throwing kernels of popcorn to pigeons at fixed intervals in a vain attempt to produce stereotyped superstitious responses of the sort described by Skinner (1948). Instead of idiosyncratic responses, the pigeons showed species-typical groundsearching behavior combined with responses that appeared to reflect a conflict between staying near the popcorn location and moving their search away in widening spirals. Taking this afternoon diversion into the laboratory gradually revealed that the traditional analysis of superstitious behavior was quite incomplete (Timberlake \& Lucas, 1985). The behavior produced by the periodic delivery of food was consistent across birds rather than predominately idiosyncratic (Skinner, 1948) and, at least in female pigeons, did not take the form of anticipatory pecking (Staddon \& Simmelhag, 1971).

Observations of the relationship between response form and inferred ecological function in unconstrained settings also can be used to explain and predict responses that emerge in conditioning. In the superstition paradigm discussed above, the female pigeons almost exclusively showed wall-directed behavior, including bumping, pressing, head bobbing, and stepping, often with wings half-drawn. Despite over 20 experiments examining determinants of this behavior, its functional context remained mystifying until we observed similar behavior in young (10-20 days) squabs begging from their parents (Mondloch \& Timberlake, 1991) and in mature females begging from males in courtship. Although these observations did not prove that wall-directed behavior in adult pigeons was related to food-begging behavior, they did directly lead to further experiments that provided evidence supporting this view.

In this last series of (unpublished) experiments, the female pigeons engaged in more wall-directed nonpecking behavior than the males-an effect expected if this be- 
havior is related to a food-begging function because adult females show more begging than males. Ring doves, a member of the same genus as pigeons, showed similar wall-directed behavior, but chickens, a different genus, showed only scratching and pecking. This was predicted from a consideration of differences in the feeding systems of the two species. Parent-young feeding in ring doves is similar to that of pigeons, but hatchling chickens are precocial, almost immediately feeding on their own by pecking and scratching at food on the ground.

Similarly, the close observation of mother hens and their chicks provided the grounds for Hogan's (1974) recognition of the response form with which baby chickens came to peck and "snuggle" a lighted key that predicted heat (Wasserman, 1973). The chicks' learned responses to the key resembled those directed to a brooding hen by chicks seeking to get beneath her feathers. As a final example, observation of seven rodent species interacting with live prey made it possible to predict the form and relative amount of interaction of the species with an artificial moving stimulus that predicted laboratory food pellets (Timberlake \& Washburne, 1989).

\section{Integration of Ethological and Psychological Approaches to Learning}

A final benefit of observation of response form and inference of ecological function in animal learning is that they may facilitate the integration of ethological philosophies and methods with those of animal learning (Bolles, 1988; Galef, 1989; Gould, 1986; Kamil, Krebs, \& Pulliam, 1987; Lehner, 1979; Rozin \& Schull, 1988; Snowdon, 1983; Timberlake, 1993a). Although the case for integration has been made with great persuasiveness by many researchers, including Tinbergen (1951), Miller (1977), and Kamil (1988), progress has been surprisingly slow (Galef, 1989; Timberlake, 1993a). Scientists from both approaches agree that a major aim of research is to understand how the behavior of an animal changes to fit its environment. Unfortunately, they disagree about the major determinants of this fit and how to study it. As documented above, ethologists have emphasized the role of evolution in driving the behavior-environment fit in natural settings. Psychologists have focused on the role of learning mechanisms in explaining presumably arbitrary behavior in artificial laboratory environments.

As many have recognized, these different approaches to the study of learning provide elements of a complementary match (Timberlake, 1993a; but see Galef, 1989; Shettleworth, 1989). Mechanisms do not exist independently of an animal's ecology and evolution, and function and evolution are always based on specific mechanisms (Rozin \& Schull, 1988). Observation of behavioral form can reveal aspects of ontogeny, evolution, and function that are difficult to appreciate when using isolated environmentally defined response units. On the other hand, definition of responding in terms of simple environmental effects can facilitate data collection and analysis, help quantify and dissect the effects of causal mechanisms, and enable tests of functional relations (Martin \& Bateson, 1993).

In fact, scientists have begun to exploit the opportunities available in an integration of these approaches. Researchers interested in ethology and behavioral ecology have begun to take advantage of the power of environmentally defined responses, standardized apparatus, and refined experimental paradigms to control and manipulate the variables that affect the foraging behavior of animals (Cassini, Kacelnik, \& Segura, 1990; Collier, 1983; Fantino \& Abarca, 1985; Olson, 1991; Pietrewicz \& Kamil, 1977). A smaller number of learning researchers have adopted the regular use of observation to study both form of responding and its ecological function (Breland \& Breland, 1966; Domjan, Lyons, North, \& Bruell, 1986; Galef, 1989; Holland, 1984; Hollis, 1990; Shettleworth, 1975; Timberlake \& Lucas, 1985).

An important area in which observation of form and inference of function may contribute to an integrative approach is the comparative study of learning. Generally, psychologists have used standard experimental paradigms and environment-based response measures to order species according to learning capacity (see Kamil, 1988; Shettleworth, 1993b; Timberlake, 1993a). In contrast, ethologists have used similarities of response form and ecological function to look at convergent adaptation and behavioral homology among different species, with little attention to learning. Merely adding observation of response form and inference of function to typical laboratory situations may assist in developing the study of convergent and homologous aspects of learning in the laboratory. This approach is likely to be especially important in research on the genetic bases of behavior, in which the form and function of behavior may be an index of inheritance (e.g., Arnold, 1980; Dilger, 1960). The comparative study of learning also has received a large boost from researchers who use laboratory techniques in seminatural conditions to compare learning and memory in related and unrelated species (Balda \& Kamil, 1989; Krebs, Healy, \& Shettleworth, 1990; see also Kamil, 1988, and Shettleworth, 1990, but also Riley \& Langley, 1993).

It may be that a critical impediment to the integration of the approaches of psychology and ethology to the study of learning has simply been a lack of familiarity that researchers have with each others' methods. The melding of laboratory techniques with studies of functional behavior in seminatural conditions gets around this obstacle. Concern with response form and ecological function in the experimental paradigms of laboratory learning also may help. Descriptive and analytic approaches such as the study of behavior systems can help in conceptualizing both naturally occurring behavior and the results of laboratory analyses, thus providing a common framework connecting mechanism and function across diverse environments and procedures. Researchers working on different aspects of learning may become more aware of common functional 
issues and potential relations. The extensive work on song learning in birds has many components of such an integration (Beecher, 1990; Marler, 1991; Nottebohm, 1991).

\section{OBJECTIONS TO OBSERVATION}

Given the potential advantages outlined above, why have observation of behavior and a concomitant interest in form and ecological function not been adapted more widely in the study of animal learning? Our conversations with students and researchers and our reading of historical literature suggest that observation of response form and inference of function are frequently perceived as (1) unnecessary for scientific study, (2) not relevant to the central issues of learning, and (3) unscientific and impressionistic-a dangerous doorway through which processing errors, interpretative bias, motivated mistakes, and story-like explanations can creep into a rigorous scientific endeavor.

\section{Observation as Unnecessary for Scientific Study}

A frequent objection to the use of observation is that it is unnecessary for and even a tedious hindrance to the study of learning. Researchers have been highly successful when using simple operational definitions of concepts and automated recording of environmentally defined responses in standardized apparatus. This approach allows many subjects to be run at the same time, and their data can be automatically recorded and stored for analysis.

Although we agree that the success of learning research has been considerable, any assertion that observation is not an important part of the traditional approach is misleading. In actual practice, observation of behavior, including noting its form and inferring at least its local function, is a significant part of learning research.

As pointed out previously, observation is frequently used for data collection when automatic techniques are too expensive, unreliable, or difficult to implement (see, e.g., Renner \& Seltzer, 1991). Observation is also the primary technique for screening the health of experimental subjects. More specific to learning issues, observation is critical for shaping behavior. Several researchers have noted that shaping is an acquired skill, a technique developed with experience that produces much better results than initial efforts (Midgley, Lea, \& Kirby, 1989; Pear \& Legris, 1987; Stokes \& Balsam, 1991). It seems unlikely that experienced researchers become more proficient at shaping because they develop an increasingly better theoretical understanding of reinforcement. A more likely explanation is that the experienced shaper has watched subjects enough to recognize the forms and sequences of responses they emit at particular times in particular circumstances (a sort of constrained ethogram). Experienced researchers use form and its inferred function to modify their subsequent procedures to shape responding.

Researchers routinely employ observation as part of the ongoing process of tuning the experimental procedures and apparatus to produce reliable and robust behavior.
As mentioned, Boakes (1977) relocated the light that cued leverpressing in order to encourage pressing rather than nosing of the lever, and Skinner (1956) used extensive observation to develop a reliable leverpressing response. In general, observation provides information about why one animal responds differently than another, or why changing the apparatus or procedure produces different outcomes than were anticipated.

Concern with the form and function of behavior has made accounts of superstition, misbehavior, and stimulus substitution much more compelling. For example, Skinner (1948) extensively described idiosyncratic responses of pigeons under fixed-time food delivery to support his argument that superstitious behavior was based on arbitrary associations between responses and reinforcers. Skinner reported that his pigeons showed counterclockwise turning, head thrusts toward an upper corner, repeated head tossing, pecking or brushing motions toward the floor, and "a pendulum motion of the head and body, in which the head was extended forward and swung from right to left with a sharp movement followed by a somewhat slower return"' (p. 168).

Breland and Breland's (1961, 1966) descriptions of the topography and potential ecological function of misbehavior, such as the repeated washing of tokens by a raccoon, were equally important in convincing scientists of its significance. Stimulus-substitution accounts of response form in Pavlovian conditioning explicitly require comparison of the form of the conditioned response to the form of the unconditioned response. For example, Pavlov (1927) described a resemblance between how dogs licked a light bulb paired with food and how they licked food in a dish. Evidence against a simple stimulus-substitution view also comes from observation of response form. Wasserman (1973) found that chicks snuggled a keylight that predicted brief exposure to a heat lamp, even though they sprawled on the ground with wings outstretched when the heat light came on.

In short, the practice of research regularly involves observation of the form of behavior and inference of its function in adjusting procedures and measures, in generating explanations and hypotheses, and in making convincing points. However, in reporting and analyzing experiments, most learning researchers use observation (if at all) only as a convenient substitute for automatic recording. Thus, although data about the form and function of behavior are generated informally by the researcher, such observations are not typically treated as primary data. Rather than continue this inconsistent stance, it would seem better to incorporate data about response form and function directly into our hypotheses and theories.

\section{Observation as Irrelevant to the Central Issues of Learning}

When reminded how frequently they depend on observation of response form and inference of function, researchers may acknowledge its importance but still argue that observation is of marginal relevance to the study 
of learning (Lee, 1992). This opinion appears to hinge on two general arguments. The first argument stems from the associationist view that topography and function have to do with issues of performance, whereas the primary goal of learning research is to specify the mechanisms and laws underlying the formation of associations independent of performance rules.

There are at least three rebuttals to this argument. The first simply disputes that learning is best viewed only as the development of associations between internal representations of stimuli, responses, and rewards. For example, operant psychologists argue that the inaccessibility of associations and representations makes them susceptible to the invention of causes that reside more in the experimenter's explanations than in the animal's behavior. Biologists might argue that specific functional forms of learning, such as song learning in birds, do not appear best characterized as a set of simple associations or representations. The changes that accompany birds' song learning occur at levels of input, output, and processing in different anatomical structures and over different time frames (Nottebohm, 1991).

The second rebuttal is that disentangling learning from performance requires a considerably more sophisticated and specific understanding of performance than currently exists. For example, Stokes and Balsam (1991) used systematic observation to establish that elements of the topography of leverpressing in rats were present before the explicit contingency was imposed. The effect of the contingency was to assemble and integrate existing sets of complex response components rather than create responding out of random motions. Consideration of the topography of behavior and its evolutionary function may well be critical in the development of more complex and specific rules of performance. An advanced understanding of learning will demand an advanced understanding of performance.

Third, there are compelling arguments that learning evolved within the context of an already functioning system of behavior (Nottebohm, 1972; Timberlake \& Lucas, 1989; Tinbergen, 1951). What was selected for in evolution was the behavior of the functioning system, not an isolated internal mechanism of association. On these grounds, an increased understanding of the rules governing behavior is likely to lead to an increased appreciation for the complexity and interrelatedness between learning and a functioning animal.

The second general argument against studying form and function in learning is the extreme constructionist view that form and function are secondary characteristics of responding, produced accidentally or intentionally by operant reinforcement contingencies (Hull, 1935; Skinner, 1953). For example, although leverpressing in rats is defined only as a class of movement involving operation of a microswitch, food inevitably follows some response form that should then increase in strength through repeated pairings. Similarly, the ecological function of a response is presumed to be determined by deprivation procedure, and its form of expression is presumed to be based on the action of reinforcement in constructing and maintaining arbitrary chains of operant responses. There is difficulty with this argument in cases in which reliable operantlike responding emerges from a Pavlovian contingency and imposition of a negative response contingency fails to eliminate it (e.g., autoshaped keypecking; Williams \& Williams, 1969).

A related difficulty emerges from close analysis of the practice of shaping behavior. Proficient shapers (like the late B. F. Skinner) spend considerable time carefully fitting their shaping procedures to the stimulus sensitivities and response components of the animals, rather than depending on the power of reinforcement to construct any random behavior. In a conversation with one of the present authors (W.T.), Skinner recounted that an important difficulty arose in training the rat Pliny to deposit a marble into a small slot in the floor of the cage. The rat had problems releasing the marble and repeatedly tried to retrieve it as it disappeared down the slot (an appropriate behavior for a predator with escaping prey). On the basis of close observation of the form and stimulus control of the rat's retrieval behavior, Skinner solved the problem by building a small "chimney" around the slot so that the marble was not visible as it disappeared. A final weakness of the extreme constructionist view is that it does not as effectively promote contact with the evolutionary history, development, or neurophysiology of behavior.

In sum, there is considerable evidence that observation of the form of behavior and inference of its function are not irrelevant to the study of learning, even when the focus is on associations or operant response classes (see Bindra, 1961, and Miller, 1977, for further arguments). For example, close observation and tuning appear to be critical in the shaping of "well-behaved" operants. Further, given that the distinction between learning and performance has become increasingly complex and important (see Miller \& Barnet, 1993), the role of observation in analyzing learning is likely to increase as well.

\section{Observation and Inference of Function as Unscientific}

Having fought to make the study of learning respectable by eliminating the subjectivity of introspection and anthropomorphism, most psychologists have been reluctant to adopt techniques that appear to be a regression to an earlier stage of scientific inquiry. Researchers strongly prefer to remain aligned with technologically sophisticated and respected disciplines such as biology and neuroscience (McPherson, 1992). Four general objections have been raised regarding the observation of response form and in ference of function. First, researchers are concerned that observation lacks the objective precision and reliability of recording environmentally defined responses (Gellert, 1955). Second, observation does not fit well with the tradition of operational definitions. Third, observation is often treated as an alternative or precursor to experimentation (Nowlis, 1960; Schneirla, 1950), rather than as a method to accompany and improve experimen- 
tation. Fourth, attempts to infer response function are perceived as problematic at best.

Observation as imprecise and unreliable. On the one hand, there seems to be little question that observation is more susceptible than microswitch closure to error factors such as experimenter fatigue, reaction time, and information overload caused by the speed and number of events. Human observers of complex events frequently act less as recorders of data than as reconstructors of the event, allowing considerable leeway for the operation of personal schemas (Loftus, 1979). Further, the categories, strategy, and even scoring of observation may vary with the interests and hypotheses of the observer. For example, LoLordo and Ross (1990) reported errors in the scoring of their observational data that may have been introduced because the observer was aware of the purpose of the experiment and the group assignment of the subjects.

However, similar criticisms can be raised against the use of automatic recording of environmentally defined responses. In the case of reliability, microswitches break or fall out of adjustment, electronics fail, cumulative recorders run out of ink, photocells become occluded or burn out, and data rates exceed the response time of the transducer. Admittedly, such errors may occur at a lower rate in automatic recording than in observation, but this is certainly not a foregone conclusion. Some of the precision of automatic recording is due to the fact that particular measurements have been extensively debugged, and the experimenters have had considerable experience in compensating for potential weaknesses. Also, experimenters test transducers and examine their data output on a daily basis and can readily detect errors on the basis of their test programs as well as their accumulated knowledge about the expected patterns of behavior. If observers were similarly tested, their output similarly debugged, and their data displayed and examined by an experienced observer on a daily basis, observational errors also would be minimized.

The requirements for good observation are refinement of categories, good habits in the daily inspection of data, and the use of trained observers to produce satisfactory levels of reliability (Kazdin, 1982; Lehner, 1979; Renner \& Seltzer, 1991). Many of the techniques used in applied behavior analysis, which evolved from the study of animal learning (G. L. Martin \& Pear, 1992), are based upon the use of human observers (see Hartmann, 1982). In fact, direct observation has been hailed as the hallmark of applied behavior analysis (Cimenero, Calhoun, \& Adams, 1977) and as the greatest contribution of behavior modification to the treatment of human problems (Johnson \& Bolstad, 1973). This reliance on observation has not retarded the development of experimentation within applied behavior analysis or made it an inferior approach, but has motivated researchers in the field to develop techniques for minimizing any subjective element or error introduced into recording procedures (see Hartmann, 1982; Kazdin, 1982).

As to the objection that observational categories and strategies are affected by an observer's interests and hy- potheses, there is little question that this is true. But the same criticism also applies to the development of automatic measures of discrete responding. Further, within limits this is not a criticism, but a requirement of any measurement scheme. Behavior can be measured in an infinite number of ways. Relating the measurement of a phenomenon to hypotheses and questions is an essential step in science, regardless of the means of measurement. Psychologists established leverpressing and keypecking as measurement categories because they appeared to relate well to the issues of interest-general questions of prediction and control of behavior.

Questions of fundamental bias in an experimental program or type of measure typically are answered over time. Scientists, in the long run, are pragmatic. If a measure does not relate well to the variables manipulated and the questions asked, then that measure is usually modified or dropped. The critical aspect of this objection is not to observer bias in framing hypotheses, but to the potential effect of the hypothesis in biasing the actual recording of data. This possibility can and should be dealt with routinely by assessing intra- and interobserver reliability of recording and using observers who are blind to the expectations of the investigator.

The lack of well-defined concepts in observation. There is a sense in which the measures of responding stemming from observation do not satisfy measurement criteria as simply as typical experimental concepts and measures. Neither the form or ecological function of behavior, nor the process of observation lends itself to operational definition in terms of environmental effects as easily as the procedures of operant and Pavlovian conditioning. For example, a leverpress is typically defined and measured by a single environmental event-the closure of a microswitch. In contrast, the topography and the ecological function of leverpressing are not so simply defined, nor are they necessarily easily measurable along a single well agreed upon dimension.

It is worth considering, though, that the operational approach has important limitations. Clearly, agreement on how to produce and measure a concept is an important part of science. However, operationism in itself does not guarantee a connection between a particular operation and the concept it presumably represents (i.e., the issue of reliability vs. validity). Defining deprivation in terms of hours of food deprivation only predicts, at best, eating behavior in an ordinal way, provided that there are no incentive differences and the animal is not in torpor. It is even less useful for predicting differences in the form or persistence of food-getting behavior. Initial and continuing observation of behavior and its functional analysis are critical for developing and refining useful operational definitions.

The use of observation should serve two goals: (1) development of agreement in classification of topography, and (2) analysis of the relation of form and the results of stimulus manipulation to ecological function. By primarily focusing on definitional clarity and agreement, an extreme version of operationism ignores variation in form 
and its relation to function. What is needed is the melding of the strengths of traditional learning research with those of the evolutionary approach. Both operationism and automaticity of recording are compatible with the analysis of form and function, provided one agrees that both internal reliability and external validity are important in the study of behavior.

Observation as an alternative to experimentation. The traditional view that observation and experimentation are alternative approaches can be traced to two sources: (1) the historical contrast between laboratory methods and information about animals garnered from observations and anecdotes (Fabre, 1918; Jaynes, 1969; Romanes, 1882), and (2) the argument of ethologically oriented researchers regarding the importance of long and careful observation before manipulation (Lorenz, 1950). Leaving aside the issue of anecdotes, many researchers strongly encourage observation preceding experimentation (Denny \& Ratner, 1970; Skinner, 1956). But too many researchers view the beginning of experimentation as the end of observation. Observation and experimentation have not been perceived as being so distinct since the work of Spalding (1872), Lubbock (1882), and C. L. Morgan (1896).

Tinbergen (1968), for example, spent many hours observing digger wasps in their open sands environment in order to gather information about their daily lives. As part of his observations, he became interested in the curious loops the wasps made in the air before leaving their home area. He hypothesized that the aerial loops gave the wasps the opportunity to survey the landmarks near the nest site, so they could find it again. By continuing his observations while manipulating the landmarks, Tinbergen gained evidence for the ecological function of learning in provisioning offspring.

Many recent investigators have demonstrated the use of operant schedules to simulate foraging for food in more natural circumstances (Collier, 1983; Dallery \& Baum, 1991; Fantino \& Abarca, 1985; Shettleworth, 1988). In a more general statement, Timberlake and Lucas (1989) argued that from the standpoint of the animal, all foodrelated behavior in the laboratory represents foraging for food because the animal has no special source of behavior evolved specifically to deal with the laboratory. It follows that observation of and experimentation with subjects in both natural environments and conditioning chambers are useful and should produce evidence for the common set of mechanisms and processes that relate food-rewarded responses in the laboratory with that of natural foraging behavior.

In sum, observation and experimental empiricism should be continuously interactive endeavors rather than sequential or separable alternatives. Initial information about the relationship between form and ecological function is acquired through repeated observations of animals in a variety of contexts, including imposing or taking advantage of existing constraints on free behavior. In formal experiments, manipulation and observation together help experimenters focus on what questions should be asked to pro- duce rapid progress toward an understanding of the role of learning in behavior. The common goal should be the combination of concern about form and ecological function with the hard-won accomplishments of traditional learning research.

The inference of ecological function. For many researchers, the inference of ecological function seems as fraught with pitfalls as the anthropomorphic inference of animal mind at the turn of the century, or the more recent wholesale use of "just-so stories" to explain the adaptiveness of particular behaviors (Gould \& Lewontin, 1981; Riley \& Langley, 1993). Although there are dangers in drawing inferences, there are important reasons not to allow potential problems to restrict the study of learning to the investigation of general low-level mechanisms of association. It seems increasingly clear that learning is not restricted to low-level mechanisms and standard paradigms, but takes many forms that range from the conditioning of motivational states to the formation of complex cognitive inferences (Timberlake, 1993b; Wasserman, 1993).

It may be important to point out that all learning necessarily involves inference-inference of the relation of learning and behavior, inference of what is learned (e.g., learning as associations vs. representations, or temporal strings vs. spatial images), and inference of how learning elements are combined. The key to the quality of an inference lies in our ability to use and test it. On this score, the inference of ecological function differs from a simple just-so story in having testable ramifications. A just-so story is a supposition about selection pressures that works backward from the effect in relatively unconstrained fashion to explain its adaptiveness. Alternative explanations are usually not ruled out, and testing can be difficult. An ecological function is more constrained. It is based on the existence of perceptual, motor, and motivational mechanisms that have particular performance characteristics and should be predictably adaptive or maladaptive depending on the situation.

A major reason for inferring ecological function is to make the relationship of evolution, neurophysiology, and learning more testable. We previously discussed several examples of how the inference of ecological function can be related to systems of behavior in testable ways. The increasing information about the neurophysiological underpinnings of sensory processing and motor organization should provide the opportunity for more precise tests of ecological function. The work of Garcia and his colleagues on taste aversion and its potentiation provides a good example of such an approach (Garcia, 1990).

In short, we cannot avoid inference in the study of learning, although, with good reason, we need to restrict the kinds of inferences that we are willing to make. We believe that the inference of ecological function, especially when based on the specifiable and testable structure and processes of a functional system of behavior, is an important addition to the study of learning. Because the topography of a response represents a point of selection as well as a reflection of mechanism, observation of the 
form of behavior should facilitate the inference and testing of ecological function.

\section{CONSIDERATIONS IN USING OBSERVATION}

Let us suppose for the sake of argument that the reader is convinced of the virtues of observation and the importance of the study of form and ecological function. What additional issues must be dealt with to help researchers increase their use of observational techniques? The absence of a continuous observational tradition in learning research poses a distinct problem at this point. Despite classic field-related work by Watson (1908), Yerkes (1912), Carpenter (1934), Schneirla (1950), and others (Dewsbury, 1984), the study of learning lacks a strong field tradition that would encourage and provide models for how researchers become acquainted with issues of form and ecological function in particular species (although see Beecher, 1990). Admittedly, there is a tradition of interest in comparative evolutionary issues, but much of the focus has been on anthropocentric questions rather than on questions of convergence, divergence, and selection (Shettleworth, 1993b; Timberlake, 1993a; Wasserman, 1993). Researchers still relate learning in other species primarily to humans (and secondarily to rats or pigeons, e.g., Bitterman \& Couvillon, 1992).

To facilitate the study of form and function, students should be encouraged to complete courses in evolution, ethology, and behavioral ecology, and to study topics that stress direct observation and methods for dealing with issues such as interobserver agreement, experimenter bias, and procedure reliability (e.g., applied behavior analysis, small- $N$ research methods). Field experience and research with more than one species, including humans, also should facilitate a shift in orientation to a larger functional framework (Young \& Thiessen, 1991). However, a greater appreciation of the evolutionary context of behavior is no guarantee that observation will be used systematically and well. The matter is not as simple as encouraging laboratory workers to carry checklists, portable computers, and video recorders into nature or into an experimental room. There are several skills to learn and practice and many unforeseen decisions to be made.

Numerous sources describe the basic procedures for categorizing and observing behavior (Angermeier, 1984; Grier \& Burk, 1992; Hartmann, 1982; Hutt \& Hutt, 1970; Kazdin, 1982; Lehner, 1979; Marler \& Hamilton, 1966; Martin \& Bateson, 1993; Suen \& Ary, 1989). There appears to be increasing agreement that observational categories should satisfy two requirements. First, their descriptions should be clear, unambiguous, and easily taught. Categories usually specify some combination of location, posture, movement, effects, and sense-organ orientation that is couched in words that require minimal judgment on the part of the observer. Second, categories should be designed to answer specific questions rather than describe behavior completely.

Until recently, a frequent recommendation for researchers who were interested in observation was to construct a complete ethogram of their species. Without a doubt, there is much to be gained by the amount of observation and thinking required to attempt an ethogram, but for two reasons this is a very difficult initial approach. First, in the absence of strong guidance, first-time observers often feel compelled to observe everything. Frequently, the result is an unorganized pile of marginally documented checklists or videotapes. After considerable frustration, most experimenters realize that "everything" cannot be defined, much less recorded.

Second, because the nature of an ethogram is so broadly and poorly defined, observers are immediately faced with many difficult choices, such as setting a consistent and usable level of description, developing an appropriate sampling scheme (see Altmann, 1974), determining how to combine topographical and effect-based categories, and confronting on a grand scale the persistent dilemma of whether to split or "lump" categories (Lehner, 1979; Marler \& Hamilton, 1966). Rarely can such decisions be made simply on a fixed rule or computational basis (see articles in Colgan, 1978). The solution usually depends on the question that is asked and its fit with the functional structure of the animal and the theoretical assumptions of the observer.

Some help can be provided by the realization that a major purpose of observation is to develop a behavioral context that facilitates the inference of ecological function. First, focusing on the development of an organized behavior system can frequently orient and constrain observation. Rozin and Schull (1988) compared the advantage of a functional orientation to that of a beginning football player who understands the objectives of football before receiving instructions in how to perform various component tasks such as blocking and tackling. Second, a careful consideration of function requires explicit concern with the relation between laboratory investigations and behavior under more natural conditions. In the absence of such a relation, the experiment may provide little insight into mechanisms evolved to serve ecological functions.

Third, attention to a functional framework can help researchers select appropriate species and behaviors for investigation. For example, researchers interested in how nestlings' exposure to their parents affects the birds' learning of species identification should distinguish nest parasites such as cowbirds. Fourth, focusing on functional systems of behavior provides a basis for categorizing similarities and differences among behaviors. For example, lever manipulation and maze running are both related to a rat's feeding system, but they are not equivalent in how readily they occur at different times preceding food. Manipulation responses that are not closely followed by food are unlikely to persist, whereas maze running behavior has been shown to persist even when food is rare or absent (Timberlake, 1983a).

Many practical problems must be solved in order to use observation as a primary means of data acquisition. A major stumbling block is the length of the initial training period in which observers learn to categorize behavior 
and to enter data into a recording device in a timely and reliable manner. Learning to observe and record shares elements with learning to simultaneously read and type a foreign language. The output varies from the input because of mistakes in both reading the input and in converting it to appropriate output. Not only are novices poor at this task, but it is often difficult for them to see how anyone could do it speedily and reliably. Observation requires passing through a state of discomfort about one's inability to categorize and reliably record behavior until enough practice has accrued to allow the effortless coding that characterizes skilled observers. There is little question that this phase is difficult and even threatening to researchers who are used to recording clearly defined responses automatically.

A related difficulty is that observation can be very time consuming. Observation is a skill that develops slowly and must be practiced repeatedly to achieve competence. The amount of initial observations required to develop an adequate coding scheme is difficult to define a priori, though spending an hour a day for a week is usually sufficient to begin reliably identifying patterns. Subsequently, a major determinant of the time involved in using observation is how the data are recorded and stored. If a keyboard is used to enter data directly into a computer at the time of observation, then the time involved to record and store the data for a single animal can be substantially reduced. Observing the behavior of several animals at the same time, though, is more challenging. A partial solution is to videotape behavior either in real time or sampled from different subjects for later coding (Cramer, Thiels, \& Alberts, 1990; Holland, 1980; Renner \& Rosenzweig, 1986). Recent technical advances in infrared imaging, fiber optics, and computer-based recording of location and topography should make observation easier and provide access to information that previously has been difficult to obtain (Ronca, Lamkin, \& Alberts, 1993; Seeley \& Brozoski, 1989; Silva, Silva, \& Pear, 1992).

A tractable approach to observation involves three related steps. The first is to focus on a behavior system or subsystem, such as feeding or predation-in essence, compiling a tentative constrained and organized ethogram. The second step is to develop a set of categories designed to answer a functional question related to the operation of this system. The third step is to refine, reduce, and amplify categories to clarify the questions and the phenomena of interest. It is important to realize that response categories do not represent ultimate Platonic forms, fixed in topography. Information about an animal's repertoire and functional systems is acquired continuously during the experimental process. Thus, observation of behavior, no less than the development of automated recording of discrete responses, contains elements of bootstrapping. Even for skilled observers, it is important to emphasize the necessity of remaining open to the fit between measurement categories and behavior under different manipulations.

There is no replacement for the hard work of repeated observations, but often some efficiency can be achieved by beginning with a larger group of coding categories and winnowing and combining them over the course of observation. For example, the study of superstitious behavior in pigeons by Timberlake and Lucas (1985) initially led them to code 28 behaviors that included responses such as "peck inside or on the edge of the hopper opening," "bob and step back and forth in front of wall," "walk around the chamber," " tail flick," and "repeated wingflapping, sometimes with retraction of feet." However, repeated observations suggested larger functional groupings and that helped reduce the final number of codes from 28 to 9 . This smaller number of categories allowed for more cost-effective observation in terms of ease of teaching the coding scheme, recording data, and speeding the analysis, while also focusing attention on specific questions that became clear only after the initial observations.

Any dependence on human sensory equipment for data acquisition requires awareness of the characteristics of the relevant processing pathways. In the case of vision, there are important limits on resolving movements despite the powers of pattern perception that humans possess. It took the widespread use of high-speed photography to reveal that the head-bob display in desert lizards, presumed by ethologists to be fixed in patterning and timing, shows important variation related to motivation levels and between individuals (Barlow, 1977). High-speed photography was also important in showing that the form of a pigeon's conditioned responses during autoshaping can be quite different, depending on whether the unconditioned stimulus is food or water (Jenkins \& Moore, 1973). Recording and playing back video signals at different speeds also can reveal patterns and cycles of behavior occurring both at slower and faster rates than observers can easily see in real time.

A final problem, dating at least to Skinner (1938), is the concern that focusing on the form and function of specific responses is a waste of effort on the particular-an effort that could be better spent on more general issues. Yet, in most sciences the general is illuminated and modified by the particular. Domain-specific qualities of learning are likely to be as important as general qualities (Cosmides \& Tooby, 1987). Concern with the form and ecological function of responses should facilitate increased contact with the development, neurophysiology, and evolution of the processes responsible for learned behavior (Beer, Ritzmann, \& McKenna, 1993; Davis, 1984; Steinmetz, Lavond, Ivkovich, Logan, \& Thompson, 1992).

\section{CONCLUSIONS}

The dominant tradition in animal learning has not encouraged systematic observation of the form of learned behavior and inference of function, for reasons ranging from the absence of a strong and continuous field tradition to concerns about objectivity, precision, and convenience. Researchers have sought to increase the scientific status and replicability of their work by focusing on simple, environmentally defined responses, automatically measured and manipulated within a few well-defined experimental paradigms. Typically, observation of behavior 
has been used as a more flexible but less preferred alternative for gathering data, or as an unacknowledged basis for the development of apparatus, response measures, experimental procedures, and interpretations of data. Concern with the form and function of a response most often has been viewed as a potential waste of effort on the particular-an effort that might be spent better in establishing general phenomena and laws.

However, for many of the same reasons that a reflex arc is an inadequate model of the form and ecological function of a reflex (Fearing, 1930), the measurement of isolated environmentally defined responses is an inadequate representation of the form and ecological function of learning. To ignore the fact that learning occurs within a functional organization of behavioral sequences, cycles, and episodes is to presume that individual responses are independent entities linked only by the laws of learning. An isolated response that is considered without regard to its form or function cannot be the complete basis for a science of behavior (McPherson, 1992) because it places too much emphasis on the manipulations and measurement procedures of the experimenter and too little emphasis on the functioning of the animal. The unseen advantage of careful observation of the characteristics of specific responses is that general issues frequently can be most successfully illuminated by the particular. In fact, learning can be profitably viewed as a variety of specific and species-typical "rules of thumb" that produce functions approximating standard learning principles (Galef, 1990).

Although systematic observation requires considerable practice and careful decisions about category formation and data-collection strategies, it is not unnecessary, irrelevant, or unscientific. Observation provides information about the form and ecological function of learning, which can assist in its prediction and control as well as improve ties to physiological and evolutionary analyses (Zeiler, 1992). Observation can relate sequences of learned behavior in the laboratory to naturally occurring strings of appetitive behavior (Timberlake, 1990) and can help reference learning to the episodes and cycles that characterize behavior (Weiss, Ziriax, \& Newland, 1989). Because learning evolved in the context of an already functioning organism, it seems appropriate to consider this level of complexity when studying learning.

Finally, an increased use of observation does not require that researchers abandon hard-won automated recording of environmentally defined responses (Martin \& Bateson, 1993). Carefully automated measures provide an important basis for quantification of behavior and have contributed to important improvements in the precision of research and thinking. Further, many of the problems described previously are not due to the use of automatic transduction or environmental definitions of responding per se, but to the failure of learning research to make contact with ecological function and evolution. We recommend strongly that scientists interested in learning include in their arsenal of methods the observation of form and inference of ecological function, thereby making contact with ethological techniques and reestablishing an earlier tradition of studying learning within the context of evolved and functioning animals.

\section{REFERENCES}

AEsop. The fables of Aesop. New York: Schocken Books. (Translation published 1966)

ALcock, J. (1993). Animal behavior: An evolutionary approach. Sunderland, MA: Sinauer.

AltmanN, J. (1974). Observational study of behaviour: Sampling methods. Behaviour, 49, 227-267.

ANGERMEIER, W. F. (1984). The evolution of operant learning and memory: A comparative etho-psychology approach. New York: Karger.

ARISTOTLE. Historia animalium (D. W. Thompson, Trans.). In J. A Smith \& W. K. Ross (Eds.) (1912), Works (Vol. 4). Oxford: Oxford University Press, Clarendon Press.

ARNOLD, S. J. (1980). The microevolution of feeding behavior. In A. Kamil \& T. Sargent (Eds.), Foraging behavior: Ecological, ethological and psychological approaches (pp. 409-453). New York: Garland STPM Press.

Balda, R. P., \& KamiL, A. C. (1989). A comparative study of cache recovery by three corvid species. Animal Behaviour, 38, 486-495.

BARBER, L. (1980). The heyday of natural history: 1820-1870 (1st ed.). New York: Doubleday.

BarLow, G. W. (1977). Modal action patterns. In T. A. Sebeok (Ed.), How animals communicate (pp. 98-134). Bloomington: Indiana University Press.

BEECHER, M. D. (1990). The evolution of parent-offspring recognition in swallows. In D. A. Dewsbury (Ed.), Contemporary issues in comparative psychology (pp. 360-380). Sunderland, MA: Sinauer.

BeER, R. D., RitzmanN, R. E., \& MCKenNa, T. (EDs.) (1993). Biological neural networks in invertebrate neuroethology and robotics. Boston: Academic Press.

BergmanN, G., \& SPENCE, K. W. (1941). Operationism and theory in psychology. Psychology Review, 48, 1-14.

BINDRA, D. (1961). Components of general activity and the analysis of behavior. Psychological Review, 68, 205-215.

Bitterman, M. E., \& Couvillon, P. A. (1992). Failures to find evidence of adaptive specialization in the learning of honeybees. In L. J. Goodman \& R. C. Fisher (Eds.), The behavior and physiology of bees (pp. 288-305). Wallingford, U.K.: CAB International.

Boakes, R. A. (1977). Performance on learning to associate a stimulus with positive reinforcement. In H. Davis \& H. M. B. Hurwitz (Eds.), Operant-Pavlovian interactions (pp. 67-101). Hillsdale, NJ: Erlbaum.

Bolles, R. C. (1988). Nativism, naturalism, and niches. In R. C. Bolles \& M. D. Beecher (Eds.), Evolution and learning (pp. 1-15). Hillsdale, NJ: Erlbaum.

BorING, E. G. (1968). The influence of evolutionary theory upon American psychological thought. In S. Persons (Ed.), Evolutionary thought in America (pp. 268-298). New Haven: Yale University Press.

Breland, K., \& BRELAND, M. (1961). The misbehavior of organisms. American Psychologist, 16, 681-684.

Breland, K., \& Breland, M. (1966). Animal behavior. New York: Academic Press.

CARPENTER, C. R. (1934). A field study of the behavior and social relations of the howling monkeys. Comparative Psychology Monographs, 10(No. 2).

Cassini, M. H., Kacelnik, A., \& Segura, E. T. (1990). The tale of the screaming hairy armadillo, the guinea pig, and the marginal value theorem. Animal Behaviour, 39, 1030-1050.

Ciminero, A. R., Calhoun, K. S., \& Adams, H. E. (Eds.) (1977). Handbook of behavioral assessment. New York: Wiley.

Colgan, P. W. (1978). Quantitative ethology. New York: Wiley. Collier, G. (1983). Life in a closed economy: The ecology of learn- 
ing and motivation. In M. D. Zeiler \& P. Harzem (Eds.), Advances in analysis of behaviour: Vol. 3. Biological factors in learning (pp. 223-274). Chichester, U.K.: Wiley.

COSMIDES, L., \& TOOBY, J. (1987). From evolution to behavior: Evolutionary psychology as the missing link. In J. Dupre (Ed.), The latest on the best (pp. 279-306). Cambridge, MA: MIT Press.

Craig, W. (1918). Appetites and aversions as constituents of instincts. Biological Bulletin, 34, 91-107.

Cramer, C. P., Thiels, E., \& Alberts, J. R. (1990). Weaning in rats: 1. Maternal behavior. Developmental Psychobiology, 23, 479-493.

DALLERY, J., \& BAUM, W. M. (1991). The functional equivalence of operant behavior and foraging. Animal Learning \& Behavior, 19 , 146-152.

DARWIN, C. (1859). The origin of species by means of natural selection. London: Murray.

DAvIS, W. J. (1984). Motivation and learning: Neurophysiological mechanisms in a "model" system. Learning \& Motivation, 15, 377-393.

DenNy, M. R., \& RATNer, S. C. (1970). Comparative psychology: Research in animal behavior. Homewood, IL: Dorsey.

Dewsbury, D. A. (1984). Comparative psychology in the twentieth century. Stroudsburg, PA: Hutchinson Ross.

DEWSBURY, D. A. (1992). Essay on contemporary issues in ethology. Ethology, 92, 89-107.

Dilger, W. C. (1960). The comparative ethology of the African parrot genus Agapornis. Zeitschrift für Tierpsychologie, 17, 649-685.

DomJaN, M., \& Holus, K. L. (1988). Reproductive behavior: A potential model system for adaptive specializations in learning. In R. C. Bolles \& M. D. Beecher (Eds.), Evolution and learning (pp. 213237). Hillsdale, NJ: Erlbaum.

Domjan, M., Lyons, R., North, N. C., \& Bruell, J. (1986). Sexual Pavlovian conditioned approach behavior in male Japanese quail (Coturnix coturnix japonica). Journal of Comparative Psychology, $100,413-421$.

DUNLAP, K. (1919). Are there any instincts? Journal of Abnormal Psychology, 14, 307-311.

ElDRIDGE, G. D., \& PEAR, J. J. (1987). Topographical variations in behavior during autoshaping, automaintenance, and omission training. Journal of the Experimental Analysis of Behavior, 47, 319-333.

FABRE, J.-H. (1918). The wonders of instinct. New York: The Century Co.

FANSELOW, M. S. (1989). The adaptive function of conditioned defensive behavior: An ecological approach. In R. J. Blanchard, P. F. Brain, D. C. Blanchard, \& S. Parmigiani (Eds.), Ethoexperimental approaches to the study of behavior (pp. 151-166). Boston: Kluwer Academic.

FANSELOW, M. S. (1991). The midgrain periaqueductal gray as a coordinator of action in response to fear and anxiety. In A. Depaulis \& R. Bandler (Eds.), The midbrain periaqueductal gray matter: Functional, anatomical and immunohistochemical organization (pp. 151173). New York: Plenum.

FANSELOW, M. S., \& LESTER, L. S. (1988). A functional behavioristic approach to aversively motivated behavior: Predatory imminence as a determinant of the topography of defensive behavior. In R. C. Bolles \& M. D. Beecher (Eds.), Evolution and learning (pp. 185-212). Hillsdale, NJ: Erlbaum.

Fantino, E., \& AbarCa, N. (1985). Choice, optimal foraging, and the delay-reduction hypothesis. Behavioral \& Brain Sciences, 8, 315-330.

FEARING, F. (1930). Reflex action: A study in the history of physiological psychology. New York: Hafner.

GALEF, B. G. (1989). Laboratory studies of naturally-occurring feeding behaviors: Pitfalls, progress and problems in ethoexperimental analysis. In R. J. Blanchard, P. F. Brain, D. C. Blanchard, \& S. Parmigiani (Eds.), Ethoexperimental approaches to the study of behavior (pp. 51-77). Boston: Kluwer Academic.

GALEF, B. G. (1990). A historical perspective on recent studies of social learning about foods by Norway rats. Canadian Journal of Psychology, 44, 311-329.

GARCIA, J. (1990). Learning without memory. Journal of Cognitive Neuroscience, 2, 287-305.

GELLERT, E. (1955). Systematic observation: A method in child study. Harvard Educational Review, 25, 179-195.
Glenn, S. G., Ellis, J., \& Greenspoon, J. (1992). On the revolutionary nature of the operant as a unit of behavioral selection. American Psychologist, 47, 1329-1336.

Gormezano, I., \& Kehoe, E. J. (1975). Classical conditioning: Some methodological-conceptual issues. In W. K. Estes (Ed.), Handbook of learning and cognitive processes: Vol. 2. Conditioning and behavior theory (pp. 143-179). Hillsdale, NJ: Erlbaum.

GoutD, J. L. (1986). The biology of learning. Annual Review of Psychology, 37, 163-192.

Gould, S. J., \& LeWonTIN, R. C. (1981). The spandrels of San Marco and the Panglossian paradigm: $A$ critique of the adaptationist programme. Proceedings of the Royal Society of London: Series B, 205, 581-598.

GrIER, J. W., \& BURK, T. (1992). Biology of animal behavior (2nd ed.). St. Louis: Mosby-Year Book.

Hailman, J. P. (1967). The ontogeny of an instinct. Behaviour (Suppl. 15), 1-159.

HartmanN, D. P. (Ed.) (1982). Using observers to study behavior. San Francisco: Jossey-Bass.

Heinroth, O. (1985). Contributions to the biology, especially the ethology and the psychology of the anatidae. In G. M. Burghardt (Ed.), Foundations of comparative psychology (pp. 246-301). New York: Van Nostrand Reinhold. (Original work published 1910)

Hilgard, E. R., \& MARQUis, D. G. (1940). Conditioning and learning. New York: Appleton-Century.

HiNDE, R. A. (1970). Animal behaviour: A synthesis of ethology and comparative psychology (2nd ed.). New York: McGraw-Hill.

Hogan, J. A. (1974). Responses in Pavlovian conditioning studies. Science, 186, 156-157.

Holland, P. C. (1979). Differential effects of omission contingencies on various components of Pavlovian appetitive conditioned behavior in rats. Journal of Experimental Psychology: Animal Behavior Processes, 5, 178-193.

Holland, P. C. (1980). Influences of visual conditioned stimulus characteristics on the form of Pavlovian conditioned responding in rats. Journal of Experimental Psychology: Animal Behavior Processes, 6, 81-97.

Holland, P. C. (1984). Origins of Pavlovian conditioned behavior. In G. H. Bower (Ed.), The psychology of learning and motivation (Vol. 18, pp. 129-173). Englewood Cliffs, NJ: Prentice-Hall.

HoLLIS, K. L. (1982). Pavlovian conditioning of signal-centered action patterns and autonomic behavior: A biological analysis of function. Advances in the Study of Behavior, 12, 1-64.

HoLLIs, K. L. (1990). The role of Pavlovian conditioning in territorial aggression and reproduction. In D. A. Dewsbury (Ed.), Contemporary issues in comparative psychology (pp. 197-219). Sunderland, MA: Sinauer.

HoLT, E. B. (1931). Animal drive and the learning process. New York: Holt.

HuLL, C. L. (1935). Special review: Thorndike's fundamentals of learning. Psychological Bulletin, 32, 807-823.

HUNTINGFORD, F. A. (1984). The study of animal behaviour. London: Chapman \& Hall.

HUNZAKER, D. (1962). Ethological isolating mechanisms in the Sceloporus torquatus group of lizards. Evolution, 16, 62-74.

HutT, S. J., \& HuTT, C. (1970). Direct observation and measurement of behavior. Springfield, IL: Thomas.

HuXLEY, J. S. (1914). The courtship habits of the Great Crested Grebe (Podiceps cristatus); with an addition to the theory of sexual selection. Proceedings of the Zoological Society of London, 35, 491-562.

IVERSEN, I. H. (1992). Skinner's early research: From reflexology to operant conditioning. American Psychologist, 47, 1318-1328.

JAYNES, J. (1969). The historical origins of "ethology" and "comparative psychology." Animal Behaviour, 17, 601-606.

JENkINS, H. M., \& MoORE, B. R. (1973). The form of the auto-shaped response with food or water reinforcers. Journal of the Experimental Analysis of Behavior, 20, 163-181.

JENSSEN, T. A. (1978). Display diversity in anole lizards and problems of interpretation. In N. Greenberg \& P. D. Maclean (Eds.), Behaviour and neurology of lizards (pp. 269-286). Rockville, MD: Dept. of Health, Education, \& Welfare. 
Johnson, S. M., \& Bolstad, O. D. (1973). Methodological issues in naturalistic observation: Some problems and solutions for field research. In L. A. Hamerlynck, L. C. Hardy, \& E. J. Mash (Eds.), Behavior change: Methodology, concepts, and practice (pp. 7-67). Champaign, IL: Research Press.

JoHnston, T. D. (1981). Contrasting approaches to a theory of learning. Behavioral \& Brain Sciences, 4, 125-173.

JoHNSTON, T. D. (1985). Introduction: Conceptual issues in the ecological study of learning. In T. D. Johnston \& A. T. Pietrewicz (Eds.), Issues in the ecological study of learning (pp. 1-24). Hillsdale, NJ: Erlbaum.

KamiL, A. C. (1988). A synthetic approach to animal intelligence. In D. W. Leger (Ed.), Nebraska symposium on motivation, 1987: Comparative perspectives in modern psychology ( $\mathrm{pp} .257-308$ ). Lincoln, NE: University of Nebraska Press.

Kamil, A. C., Krebs, J. R., \& Pulliam, H. R. (Eds.) (1987). Foraging behavior. New York: Plenum.

KAZDIN, A. E. (1982). Single-case research designs: Methods for clinical and applied settings. New York: Oxford University Press.

KIPLING, R. (1894). The jungle book. New York: Doubleday.

Krebs, J. R., Healy, S. D., \& Shettleworth, S. J. (1990). Spatial memory of Paridae: Comparison of a storing and a nonstoring species, the coal tit, Parus ater, and the great tit, P. major. Animal Behaviour, 39, 1127-1137.

Kuo, Z. Y. (1921). Giving up instincts in psychology. Journal of Philosophy, 18, 645-664.

LEE, V. L. (1992). Transdermal interpretation of the subject matter of behavior analysis. American Psychologist, 47, 1337-1343.

LEHNER, I. I. (1979). Handbook of ethological methods. New York: Garland STPM Press.

Lehrman, D. S. (1971). Behavioral science, engineering, and poetry In E. Tobach, L. R. Aronson, \& F. Shaw (Eds.), The biopsychology of development (pp. 459-472). New York: Academic Press.

LofTus, E. F. (1979). Eyewitness testimony. Cambridge, MA: Harvard University Press.

LoLoRDo, V. M., \& Ross, R. T. (1990). Retraction of Ross and LoLordo findings concerning blocking in serial feature-positive discriminations. Journal of Experimental Psychology: Animal Behavior Processes, 16, 402-406.

LORENZ, K. Z. (1937). The companion in the bird's world. $A u k, 54$, 245-273.

LORENZ, K. Z. (1950). The comparative method in studying innate behaviour patterns. Symposium of the Society of Experimental Biology, 4, 221-268.

Lubвоск, J. (1882). Ants, bees, and wasps. London: Kegan, Paul, \& Trench.

MacCorquodale, K., \& Meehl, P. E. (1954). Edward C. Tolman In W. K. Estes, S. Koch, K. MacCorquodale, P. E. Meehl, C. G Mueller, W. N. Schoenfeld, \& W. S. Verplank, Modern learning the ory (pp. 117-266). New York: Appleton-Century-Crofts.

MARLER, P. (1991). Song learning behavior: The interface with neuroethology. Trends in Neuroscience, 14, 100-206.

Marler, P., \& Hamilton, W. J. (1966). Mechanisms of animal behavior. New York: Wiley.

MARR, M. J. (1992). Behavior dynamics: One perspective. Journal of the Experimental Analysis of Behavior, 57, 249-266.

Martin, G. L., \& PeAR, J. J. (1992). Behavior modification: What it is and how to do it (4th ed.). Englewood Cliffs, NJ: Prentice-Hall.

MARTIN, P., \& BATESON, P. (1993). Measuring behavior: An introductory guide ( 2 nd ed.). Cambridge: Cambridge University Press.

McPherson, M. W. (1992). Is psychology the science of behavior? American Psychologist, 47, 329-335.

MidGley, M., LeA, S. E. G., \& KiRBY, R. M. (1989). Algorithmic shaping and misbehavior in the acquisition of token deposit by rats. Journal of the Experimental Analysis of Behavior, 52, 27-40.

MILLER, D. B. (1977). Roles of naturalistic observation in comparative psychology. American Psychologist, 32, 211-219.

MilleR, R. R., \& BARNet, R. C. (1993). The role of time in elementary associations. Current Directions in Psychological Science, 2, 106-111.

Mondloch, C. J., \& Timberlake, W. (1991). The effect of parental food supply on parental feeding and squab growth in pigeons (Columba livia). Ethology, 88, 236-248.

Morgan, C. L. (1896). Habit and instinct. London: Edward Arnold. MoRgAN, C. L. (1900). Animal behaviour. London: Edward Amold.

Morgan, L. H. (1868). The American beaver and his works. Philadelphia: Lippincott.

MounTJoy, P. T. (1980). An historical approach to comparative psychology. In M. R. Denny (Ed.), Comparative psychology: An evolutionary analysis of animal behavior (pp. 1-17). New York: Wiley.

Myers, A. K. (1959). Avoidance learning as a function of several training conditions and strain differences in rats. Journal of Comparative \& Physiological Psychology, 52, 381-386.

Noттевонм, F. (1972). The origins of vocal learning. American Naturalist, 106, 116-140.

Noттевонм, F. (1991). Reassessing the mechanisms and origins of vocal learning in birds. Trends in Neuroscience, 14, 206-211.

Nowlis, V. (1960). Methods for the objective study of drug effects on group functioning. In L. Uhr \& J. G. Miller (Eds.), Drugs and be haviour. New York: Basic Books.

Olson, D. J. (1991). Species differences in spatial memory among Clark's nutcrackers, scrub jays, and pigeons. Journal of Experimental Psychology: Animal Behavior Processes, 17, 363-376.

Pavlov, I. (1927). Conditioned reflexes (G. V. Anrep, Trans.). London: Oxford University Press.

Pear, J. J., \& Legris, J. A. (1987). Shaping by automated tracking of an arbitrary operant response. Journal of the Experimental Analysis of Behavior, 47, 241-247.

Peckham, G. W., \& Peckham, E. G. (1905). Wasps: Social and solitary. New York: Houghton Mifflin.

Pierrel, R., \& Sherman, J. G. (1963). Barnabus, the rat with college training. Brown Alumni Monthly, Brown University.

Pietrewicz, A. T., \& Kamil, A. C. (1977). Visual detection of cryptic prey by blue jays (Cyanocitta cristata). Science, 195, 580-582.

Pliny, the Elder. Natural history. Cambridge, MA: Harvard University Press. (Translation published 1949)

Plutarch. The theories of instinct. In E. C. Wilm (Ed.) (1925), The theories of instinct: $A$ study on the history of psychology (pp. 51-52). New Haven: Yale University Press.

Rat works slot machine for a living. (1937, May). Life, pp. 80-81.

ReNNer, M. J., \& RosenZWEIG, M. R. (1986). Object interactions in juvenile rats (Rattus norvegicus): Effects of different experiential histories. Journal of Comparative Psychology, 100, 229-236.

ReNNER, M. J., \& SELTZER, C. P. (1991). Molar characteristics of exploratory and investigatory behavior in the rat (Rattus norvegicus). Journal of Comparative Psychology, 105, 326-339.

Riley, D. A., \& LANGley, C. M. (1993). The logic of species comparisons. Psychological Science, 4, 185-189.

Romanes, G. J. (1882). Animal intelligence. London: Kegan, Paul, \& Trench.

Ronca, A. E., Lamkin, C. A., \& Alberts, J. R. (1993). Maternal contributions to sensory experience in the fetal and newborn rat (Rattus norvegicus). Journal of Comparative Psychology, 107, 61-74.

Rozin, P., \& SchULL, J. (1988). The adaptive-evolutionary point of view in experimental psychology. In R. C. Atkinson, R. J. Herrnstein, G. Lindzey, \& R. D. Luce (Eds.), Stevens' Handbook of experimental psychology: Vol. 2. Learning and cognition (2nd ed., pp. 503-546). New York: Wiley.

SCHNEIRLA, T. C. (1950). The relationship between observation and experimentation in the field study of behavior. Annals of the New York Academy of Sciences, 51, 1022-1044.

SEeley, R. J., \& Brozoski, T. J. (1989). Measurement and quantification of stereotypy in freely behaving subjects: An information analysis. Behavior Research Methods, Instruments, \& Computers, 21, 271-274.

SELous, F. C. (1908). African nature notes and reminiscences. London: Macmillan.

SETON, E. T. (1913). Wild animals at home. New York: Doubleday. SEVENSTER, P. (1973). Incompatibility of response and reward. In R. A. Hinde \& J. Stevenson-Hinde (Eds.), Constraints on learning: Limitations and predispositions (pp. 265-283). New York: Academic Press. 
SHETtLeWorth, S. J. (1975). Reinforcement and the organization of behavior in golden hamsters: Hunger, environment, and food reinforcement. Journal of Experimental Psychology: Animal Behavior Processes, 1, 56-87.

SHETTLEWORTH, S. J. (1983). Function and mechanism in learning. In M. Zeiler \& P. Harzem (Eds.), Advances in analysis of behavior: Vol. 3. Biological factors (pp. 1-39). New York: Wiley.

SHETTLEWORTH, S. J. (1988). Foraging as operant behavior and operant behavior as foraging: What have we learned? Psychology of Learming \& Motivation, 22, 1-49.

ShetTleworth, S. J. (1989). Animals foraging in the lab: Problems and promises. Journal of Experimental Psychology: Animal Behavior Processes, 15, 81-87.

SHETTLEWORTh, S. J. (1990). Spatial memory in food-storing birds. Proceedings of the Royal Society of London: Series B, 329, 143-151.

ShetTleworth, S. J. (1993a). Varieties of learning and memory in animals. Journal of Experimental Psychology: Animal Behavior Processes, 19, 5-14.

SheTtLEWORTH, S. J. (1993b). Where is the comparison in comparative cognition? Alternative research programs. Psychological Science, 4, 179-184.

Silva, F. J., Silva, K. M., \& Pear, J. J. (1992). Sign versus goaltracking: Effects of conditioned-stimulus-to-unconditioned-stimulus distance. Journal of the Experimental Analysis of Behavior, 57, 17-31.

SKINNER, B. F. (1932). Drive and reflex strength. Journal of General Psychology, 6, 22-37.

SKINNER, B. F. (1938). The behavior of organisms: An experimental analysis. New York: Appleton-Century-Crofts.

SKINNER, B. F. (1948). "Superstition"' in the pigeon. Journal of Experimental Psychology, 38, 168-172.

SKINNER, B. F. (1953). Science and human behavior. New York: Macmillan.

SkinNer, B. F. (1956). A case history in scientific method. American Psychologist, 11, 221-233.

SkINNER, B. F. (1974). About behaviorism. New York: Knopf.

SMaLL, W. S. (1899). An experimental study of the mental processes of the rat. American Journal of Psychology, 11, 131-165.

SNowdon, C. T. (1983). Ethology, comparative psychology, and animal behavior. Annual Review of Psychology, 34, 63-94.

Spalding, D. A. (1872). On instinct. Nature, 6, 485-486.

Staddon, J. E. R., \& Simmelhag, V. L. (1971). The "superstition" experiment: A reexamination of its implications for the principles of adaptive behavior. Psychological Review, 78, 3-43.

Steinmetz, J. E., Lavond, D. G., Ivkovich, D., Logan, C. G., \& ThOMPson, R. F. (1992). Disruption of classical eyelid conditioning after cerebellar lesions: Damage to a memory trace system or a simple performance deficit? Journal of Neuroscience, 12, 4403-4426.

StokEs, P. D., \& BALSAM, P. D. (1991). Effects of reinforcing preselected approximations on the topography of the rat's bar press. Journal of the Experimental Analysis of Behavior, 55, 213-231.

SUEN, H. K., \& ARY, D. (1989). Analyzing quantitative behavioral observation data. Hillsdale, NJ: Erlbaum.

Thorndike, E. L. (1898). Animal intelligence: An experimental study of the associative processes in animals. Psychological Review Monograph, 2(Whole No. 8).

THORNDIKE, E. L. (1911). Animal intelligence. New York: Macmillan.

THORPE, W. H. (1979). The origins and rise of ethology: The science of natural behaviour of animals. London: Heinemann.

TIMBERLAKE, W. (1983a). Appetitive structure and straight alley running. In R. L. Mellgren (Ed.), Animal cognition and behavior (pp. 165-222). Amsterdam: North-Holland.

TimBERLAKE, W. (1983b). The functional organization of appetitive behavior: Behavior systems and learning. In M. D. Zeiler \& P. Harzem (Eds.), Advances in the analysis of behavior: Vol. 3. Biological factors in learning (pp. 177-221). New York: Wiley.

TIMBERLAKE, W. (1990). Natural learning in laboratory paradigms. In D. A. Dewsbury (Ed.), Contemporary issues in comparative psychology (pp. 31-54). Sunderland, MA: Sinauer.
Timberlake, W. (1993a). Animal behavior: A continuing synthesis Annual Review of Psychology, 44, 675-708.

TimberLaKE, W. (1993b). Behavior systems and reinforcement: An integrative approach. Journal of the Experimental Analysis of Behavior, 60, 105-128.

TimberlaKe, W., \& LuCAs, G. A. (1985). The basis of superstitious behavior: Response contingency, stimulus substitution, or appetitive behavior? Journal of the Experimental Analysis of Behavior, 44, 279-299.

TimBERLAKE, W., \& LUCAs, G. A. (1989). Behavior systems and learning: From misbehavior to general principles. In S. B. Klein \& R. R Mower (Eds.), Contemporary learning theories: Instrumental conditioning theory and the impact of biological constraints on learning (pp. 237-275). Hillsdale, NJ: Erlbaum.

Timberlake, W., \& WashburNe, D. L. (1989). Feeding ecology and laboratory predatory behavior toward live and artificial moving prey in seven rodent species. Animal Learning \& Behavior, 17, 1-10.

Tinbergen, N. (1951). The study of instinct. Oxford: Oxford University Press, Clarendon Press.

Tinbergen, N. (1963). The shell menace. Natural History, 72, 28-35. Tinbergen, N. (1968). Curious naturalists. New York: Basic Books.

Tolman, E. C. (1932). Purposive behavior in animals and men. New York: Century.

Tolman, E. C. (1938). The determiners of behavior at a choice point. Psychological Review, 45, 1-41.

Tolman, E. C., \& Nyswander, D. B. (1927). The reliability and validity of maze-measures for rats. Journal of Comparative Psychology, 7, 425-460.

UeXKull, J. von (1934). Streifuge durch die Umwelten von Tieren und Menschen. Berlin: Springer-Verlag. In C. H. Schiller (Ed. and Trans.), (1957). Instinctive behavior: The development of a modern concept. New York: International Universities Press.

WARDEN, C. J. (1927). The historical development of comparative psychology. Psychological Review, 34, 57-85, 135-168.

WARNER, L. H., \& WARDEN, C. J. (1927). The development of a standardized animal maze. Archives of Psychology, 92, 1-35.

WASSERMAN, E. A. (1973). Pavlovian conditioning with heat reinforcement produces stimulus-directed pecking in chicks. Science, 181, 875-877.

Wasserman, E. A. (1993). Comparative cognition: Beginning the second century of the study of animal intelligence. Psychological Bulletin, 113, 211-228.

Watson, J. B. (1908). The behavior of noddy and sooty terns. Carnegie Publications, 103, 187-255.

WATSON, J. B. (1919). Psychology from the standpoint of a behaviorist (2nd ed.). Philadelphia: Lippincot.

Weiss, B., Ziriax, J. M., \& Newland, M. C. (1989). Serial properties of behavior and their chemical modification. Animal Learning \& Behavior, 17, 83-93.

Williams, D. R., \& Williams, H. (1969). Automaintenance in the pigeon: Sustained pecking despite contingent non-reinforcement. Journal of the Experimental Analysis of Behavior, 12, 511-520.

YERKES, R. M. (1912). The intelligence of earthworms. Journal of Animal Behavior, 2, 332-352.

YounG, P. T. (1938). Motivation of behavior: The fundamental determinants of human and animal activity. New York: Wiley.

Young, R. K., \& THIEssen, D. D. (1991). Washing, drying, and anointing in adult humans (Homo Sapiens): Commonalities with grooming sequences in rodents. Joumal of Comparative Psychology, 105, 340-344

ZEILER, M. D. (1992). On immediate function. Journal of the Experimental Analysis of Behavior, 57, 417-427.

(Manuscript received June 16, 1993; revision accepted for publication October 12, 1993.) 